\title{
Potentialities of the Finnish Higher Educational Framework for the Middle East: Requirements, Challenges, and Perspectives-Case of Oman
}

\author{
Zouhaier Slimi ${ }^{1}$ \\ ${ }^{1}$ International Maritime College Oman, Suhar, Sultanate of Oman \\ Correspondence: Zouhaier Slimi, International Maritime College Oman, P. O. Box: 532, PC: 322, Falaj Al \\ Qabail, Suhar, Sultanate of Oman. E-mail: slimizou@hotmail.com
}

Received: February 4, 2019

Accepted: March 2, 2019 Online Published: March 29, 2019

doi:10.5539/jel.v8n3p691

URL: https://doi.org/10.5539/jel.v8n3p69

\begin{abstract}
Studying the possibility of applying the Finnish Higher Education framework in the Middle East; the case of Oman requires an in-depth investigation and a clear focus on the main success factors.

The research method uses the qualitative approach to study the points of views, feeling and assumptions of all the stakeholders in the Omani educational system and how teachers perceive the idea of applying the Finnish example.

The results reveal that all participants are for using the Finnish Higher Education Framework in Oman. However, they see that the application should go through a strategic, constant long-term process along with the professional development of academic staff, the collaboration of all stakeholders and the support of the government are critical requirements.
\end{abstract}

Keywords: Finnish higher education, Omani higher education, challenge, perspectives

\section{Introduction}

Teaching and learning methods have developed historically to meet the requirements of the dynamic world. The twenty-first century, which is known for the digital revolution, has dictated new schemes for both learner and teacher such as the student-centred approach where the teacher is a facilitator, the learning is friendly, challenging and smart.

Similarly, the new world order has spelt independent learning where the learner must experience leadership, teamwork spirit, problem-solving skills, critical thinking, academic integrity and behavioural skills (Halah \& McGuire, 2015). In brief, research skills, abilities to change, being a positive universal citizen and lifelong learner are becoming essential priorities of our world (CNN, 2013). The Finnish higher education system seems to reflect a great deal in adopting these nuts and bolts according to recent studies (Pasi, 2015).

\section{Background}

This research paper investigates how possible it is to adopt the Finnish framework of higher education in Oman and what are the potential challenges and perspectives? The topic is interesting as it deals with one of the leading educational systems in the world nowadays that of Finland (William, 2014). Likewise, the study seeks to develop higher education performance in Oman and bring it the verge of international standards (Ellen Hazelkorn, 2017). Additionally, the academic tries to study how concepts applied in Finland such as autonomy, critical thinking, problem-solving, research-oriented learning and equity, apply to the Omani developing system (UNESCO, 2015). Finally, the article emanates as an inspiration from some experiences that are spellbound by the Finnish experience as the America, Singaporean and North Korean ones (Business Insider, 2017).

\section{Literature Review}

The literature done seeks to foreground the research topic within its literary milieu by critically examining different literary approaches, narrowing the focus of the investigation, clarifying the knowledge gaps and the limitations of the literature review to address the research topic. 
Indeed, the topic emerges as a requirement spelt by the dynamic changes in the educational arena worldwide and as a need of both learner and teacher to meet the demands of the twenty-first century. The structure of the literature is as below: a study of the characteristics of the Finnish Higher Educational System with a focus on teaching, learning and assessment methods.

\subsection{The Characteristics of the Finnish Higher Educational System: A Focus on Teaching, Learning and} Assessment Methods

In Brief, Finland is a country in Northern Europe located between Sweden and Russia bordering the Baltic Sea, Gulf of Inland and Gulf of Bothnia. The official language is $88.3 \%$ Finnish, 5.3\% Russian and other minor speakers of Estonian, Romani and Sami (The World Factbook, 2017).

Recently, Finland had the best Higher education quality worldwide according to PISA (Note 1) (Sahlberg, 2011). Equally, Finland ranks second after Japan in OECD (Note 2) list measuring learned skills according to a report by the BBC (2016). Similarly, referring to a study by OECD's, Finland rates second after Japan in the top 10 highest performing graduates worldwide (Sean, 2016). More than that Finland positions top in PISA performance in higher education performance, equity and efficiency along with Germany, New Zealand and Japan (National Center on Education and the Economy, 2017). Additionally, Finland emerges as the top of the most robust higher education and training systems supporting economic competitiveness and growth before Singapore, Netherlands, Switzerland and Belgium (World Economic Forum, 2017).

The Finnish higher education system comprises two major sectors: 14 universities and 24 applied sciences' universities with six university centres and 13 state research centres, which pool together higher education services (Melin et al., 2015). Correspondingly, universities focus on education, academic and scientific research whereas applied sciences universities (Polytechnics) target high-quality standard of working life (The Fulbright Center, 2017). Relatedly, the Finnish higher education admission policy is challenging, and learning is rigorous with approximately $10 \%$ of secondary school students who only make it to universities (The Fulbright Center, 2017).

\subsection{The Finnish Higher Education Practical Teaching and Learning Methods}

In particular, the Finnish institutions are autonomous actors responsible for the development of their education and research methods (Ministry of Education and Culture, 2017c). Precisely, Finnish universities base their work on scientific research for both undergraduate and graduate learners and engage in educating students to serve Finland and the universe based on a philosophy of trust, autonomy, less is more, and a friendly ecosystem of learning (Suoranta \& Moisio, 2006).

What makes the Finnish higher education unique is that colleges and universities prepare students to design and support flexible learning activities in a varied learning environment. Likewise, familiarise them with the educational process, learning outcomes and assessment tools in a flexible way and within various contexts of academic teaching. Additionally, this system empowers both tutor and tutee to understand the constructive alignment in education and enables them to apply ideas in their practice to identify personal and institutional goals of developing pedagogical expertise and methods (Töytäri, Tynjälä, Piirainen, \& Ilves, 2017).

On the one hand, teaching methods endorse intensive teaching days with online seminars and study circles in the virtual learning environment plus pedagogical projects that take place to reinforce the outcomes. Add to the teaching methods encourage personal contacts with both learner and instructor (Sara Juntunen, 2017). Furthermore, it allows social communication habits and styles of learning and teaching as an example, the practice of Finnish teacher is to give more time for students to respond to questions and enable learners to think more profound and more actively (Ministry of Education and Culture, 2017a).

Relatedly, Finnish universities centre around many social organisations with one of the most comprehensive networks in Europe (The Fulbright Center, 2017). For instance, the polytechnics which belong to either municipalities or private institutions have close contacts with industry services and business to train students for professional labour markets with Bachelor, Master degree programs. Alike, applied science universities arrange adult education and open education to keep and upgrade competencies (The Fulbright Center, 2017).

Moreover, the dual system of higher education applied universities that deliver education aligned with the requirements of the surrounding environment and the universities concerned with academia with less direct obligations towards economic and societal engagement make the Finnish system unique (Melin et al., 2015).

Likewise, the consolidation and rationalisation of higher education for international competition with high profiles and flexible access may have a say in making Finland at the top of the world list in higher education. Equally, the independent legal status of universities helps improve the governance system of institutions with 
less interference from the government. Add to that, the governmental financial support for education and research by $1.9 \%$ of the GDP (Note 3) can be one of the primary reasons (Melin et al., 2015).

\subsection{The Finnish Higher Education Practical Assessment Methods}

Equally, the Finnish higher education examination system includes both formative and summative methods to ensure significant and substantial learning gains. Classroom formative assessment strengthens constructive feedback and students' roles in self-assessment (Black \& Wiliam, 2008). Hence, regular written exams, as well as equivalents such as lecture diaries, summary review, completion of exercises, home-examinations, brief-research papers, are the case (The Fulbright Center, 2017). Students are very independent and responsible for their education planning and examination. In other words, they are autonomous learners, critical thinkers, ethical leaders and team builders (Chihiro, Kashif, \& Pekka, 2017).

Furthermore, the program's content and assessment tools advocate critical thinking and interdisciplinary dialogue to enhance learning and teaching, progressive and experimental approaches to develop a research-teaching connection. Similarly, evaluation stresses collegial, participatory and reciprocal procedures to promote well-being and engage both students and staff (Finland University, 2017).

In short, the Finnish higher educational system success is due to a philosophy of teaching, learning and assessing that boosts the fundamental concepts required in this century. These concepts are trust, autonomy, critical thinking, leadership skills, teamwork spirit, research-based learning, digital learning, teaching and teacher qualities, internationalisation of education and being open to other experts and experiences worldwide are the case (Ministry of Education and Culture, 2017b). In particular, despite the success of the Finnish higher education, the system faces critical challenges due to the ageing society, lack of international staff and the lack of effort to retain highly educated expats for the internationalisation of higher education.

3.4 Omani Higher Education System: Emphasis on Teaching, Learning and Assessment Gaps as well as the Cultural, Social and Professional Challenges

Briefly speaking, Oman is a GCC (Note 4) Arab country located in Asia. Oman borders Saudi Arabia, Yemen and the United Arab Emirates. The official Omani language is Arabic and the second one is English. The Omani Higher education system consists of two segments: college of applied science and universities and colleges (Sultanate of Oman Ministry of Higher Education, 2017).

There are around six applied science colleges that focus on the following programs; international business, information technology, communication studies and design. These programs vary from college to another depending on the needs of the labour sector. Students go through a foundation programme from one to two years to prepare them for diploma and degree studies (Sultanate of Oman Ministry of Higher Education, 2017).

Concerning universities and colleges in Oman, there is only one governmental University which is Sultan Qaboos University. The other institutions are 28 with eight private universities and 20 colleges that vary from governmental to private with flexible systems of educational opportunities, a variety of programs on different academic stages: Diplomas, Bachelor's degrees and Master's degrees (Diwan of Royal Court and D. G of telecommunication and Information System, 2016).

\subsection{The Teaching and Learning Challenges Facing the Omani Higher Education}

The Omani Ministry of Education works to advance higher education in the Sultanate by expanding higher education institutions and by cooperating with the Ministry of Labour. There is a substantial investment in higher education in Oman to provide educational opportunities for both genders equally with the establishment of the Quality Assurance Council to guarantee learning quality and meet the requirements of the twenty-first century. Although, the ministry of higher education imported curriculum, recruited international instructors the needs regarding knowledge acquisitions and skills still make a challenge (Melin et al., 2015). Therefore, to improve the quality of education, many efforts are put into effects such as taking the cross-disciplinary approach, interactive pedagogy, effective educators, curriculum development and sustainable funding (Yarahmadi \& Magd, 2016).

Similarly, referring to Dowling and Almansoori (2017), education faces challenges in ensuring academic standards of the graduates, which requires a focus on the quality of teaching and learning outcomes. More significantly, there is a lack of continuous professional development for the staff internally and externally for better performance as a study by Alami (2016) reveals that $68.96 \%$ of disqualified teachers in higher education in Oman.

Additionally, institutions use inadequate assessment tools for measuring the achievements of the intended learning outcomes and graduate attributes with little inadequate benchmarking of programs' outcomes and a lack 
of data on employability. Hence, higher education institutions in Oman require the distinct identity of their graduates by embedding attributes into the learning process and making them clear for evaluation. Furthermore, developing innovative, flexible learning environment, teaching methods and practical assessment that boost learning are worth investigation (Dowling \& Almansoori, 2017).

\subsection{The Socio-Cultural and Professional Challenges Facing the Omani Higher Education}

What makes the issue worse is that Omani students are driven by marks and not by the quality of learning (Alami, 2016). Besides, when it comes to academic integrity, institutions lack adequate mechanisms to detect and prevent plagiarism in addition to the sociocultural grasp with the idea of doing work for someone is a matter of assistance and not plagiarism (Dowling \& Almansoori, 2017). Likewise, the quality of education is affected by the quality of training, an increase of administrative and academic workload, excessive paperwork, an ineffective partnership with external HEIs (Note 5) and the lack of qualified human resources (Yarahmadi \& Magd, 2016). Correspondingly, a recent study by Yarahmadi, F. and Magd (2016) reveals that Omani higher education institutions are not ready to apply total quality management that consists of seven significant principals that of collaboration, being customer focused, continuous improvement, commitment, realism, and learning (Black \& Wiliam, 2008). The above requirements dictate high-quality management to develop curriculums, examinations and evaluations systems, research and publications. Additionally, high-quality management would reinforce the autonomy of the institutions and the academic staff by making strict measures for hiring qualified staff as in Finland and enhance the quality of the learning outcomes (Yarahmadi, F., \& Magd, 2016).

Although the Omani Ministry of Higher Education is exerting lots of efforts to develop education performance management quality, knowledge acquisitions, teaching and learning quality, skills and students' performance still make a challenge (Melin et al., 2015).

\subsection{The Perspectives of Applying the Finnish Higher Education Framework of Teaching, Learning and Assessment in Higher Education in Oman}

First, the word view refers to a particular way of thinking about something, especially the one that influences our beliefs or experiences. Mostly, the aspect of applying the Finnish higher education framework has to put the focus on the influencing teaching and learning methods and environment including assessment for better quality learning outcomes. As an example, an attempt of the Omani Ministry of higher education to cooperate closely with the Finnish university of applied science Turku when Qasim Al-Mamari and Hilal Ali Al Maqbali got to know teamwork-based learning method at the business academy in Finland in 2014 (Turku AMK, 2014).

Additionally, applying the Finnish system would help bring new teaching methods, and tune educational institutions with society and industry. The latter can be translated in a visit of the Omani Minister of higher education, Rawaya Al-Busaidi to the University of applied science Turku and how she was interested in modern learning methods, in entrepreneurial tuition, and teaching and learning environments in Finnish higher education. The minister focused on student and teachers exchange, of joint research and development projects as well as in IT cooperation, health, well-being and the cultural field (Turku AMK, 2014).

To conclude, it is clear that the Finnish Higher Education quality is of inspiration for lots of reasons as it has a different teaching and learning environment based on trust and cooperation between higher institutions and academic staff.

\section{Methodology}

\subsection{Philosophy}

This research paper uses interpretivism as a theory of investigation as it is one of the core approaches of educational research which prefers humanistic qualitative methods which will rely on a focused group session with both decision makers and academic staff (Noella \& Sally, 2006). The author used the qualitative method as the topic is concerned with education which is indeed our experiences, feelings, opinions and perceptions (Punch, 2009). The qualitative method included two focused group sessions. The sampling session included four lecturers from different nationalities working for the International Maritime College Oman. Alike, the focus group panel involved six members from the same higher institution with different positions; decision makers, a manager, and lecturers from different nationalities and with variable international educational, social, and cultural backgrounds. 


\subsection{Approach}

The study uses an inductive approach that advocates the qualitative method as the topic is concerned with education which is indeed our experiences, feelings, opinions and perceptions (Punch, 2009). The qualitative method includes two focused group session. The sampling session comprises four lecturers from different nationalities working for the International Maritime College Oman. Contributors involve decision makers, a manager, and lecturers from different nationalities and with variable educational, social, and cultural backgrounds.

\subsection{Methods}

The researcher generated data on collective views within the meanings that stand behind the opinion of the participants. The discussion about how to apply the Finish Higher education framework in Oman will use two focused group sessions, guided, monitored and recorded by the researcher. The use of a focus group is to win time, interact directly with participants, ask in-depth questions to get detailed information about personal and group feelings, perceptions and opinions. Equally, it helps generate quick data and enables the researcher to study body language expressions. In short, focus group session assists in producing a richer understanding of the participants' experiences, and beliefs towards the appliance of the Finnish framework of higher education in Oman (Gill et al., 2008).

\subsection{Ethics}

Ethically, the purpose of the study is explained to all the contributors in the participants' consent form. In the same manner, the researcher focused on autonomy and confidentiality by informing the participants that they are free to participate and withdraw at any time without explaining or giving excuses (British Educational Research Association, 2011)

\section{Findings}

\subsection{Applying the Finnish Higher Education Framework in Oman}

The first outcomes of the piloting session revealed that all participants are pro the use of the Finnish System "it is a good idea to adopt the F.H.E.F (Note 6) in Oman," "it is a good idea to apply the F.H.E.F, but it is a difficult job."

Meanwhile, the other speakers appreciated the idea verbally and nonverbally as they reacted towards the opinion by saying "not a matter of system but a question of ethos." It is evident that all participants are for the concept of using the Finnish higher education framework but as they said it is a real challenge.

Participants argued that the Finnish framework advocates "academic freedom", gives "time framework" for learners to think and respond to their teacher's questions. Moreover, it is a "problem and research-based learning and teaching environment" according to one of the participants and as mentioned earlier by (Töytäri et al., 2017).

In the same context added one contributor added that the Finnish use "clear strategy in education that fits into the economy", and "they use long-term strategies" unlike Oman as inferred from his speech. Not only this but he added that the Finnish framework is useful when it comes to both soft and hard skills.

In particular, in the piloting session participants expressed their like to the Finnish educational system because it is a "sound system" with a "clear strategy", "stress-free", "advocating freedom", "research and problem-based learning environment" (Ministry of Education and Culture, 2017a).

Participants in the focus group indicated similar appreciation as the first group to the idea to adopt the Finnish Higher Education Framework in Oman as quoted below: "I think it is a good idea for sure to use the F.H.E.F in Oman." Similarly, "I would agree with everything mentioned", and "I agree with what you have said". To put it mildly, participants in the focus group as quoted above agree that adopting the Finnish higher education framework in Oman is a good idea, but it is a challenging task.

\subsection{The Finnish Practical Teaching, Learning and Assessments Methods We Can Use in Oman}

Focusing on the Finnish actual teaching, learning and assessments methods to apply in Oman, the responses were varied. For instance, candidates stressed concepts such as "problem-based learning", "group work and team spirit". Additionally, they emphasised "the efficiency of teaching and learning methods", "student-centered classes", "active assessing methods", "stress-free environment", "formative assessment", "alignment of goals with business requirements", and "benchmarking assessment on international standards". Not only this but also they added that "the culture of trust, planning and research are critical success factors". In short, question two findings reveal that participants like to use the Finnish Higher Education methods of teaching and assessments 
because it uses research-based learning, problem saved teaching, trust, stress-free environment, formative assessment, constructive feedback and international benchmarking and alignment with the external business which aligns with what Melin thinks (Melin et al., 2015).

Concerning the Finnish effective teaching, learning and assessments methods, participants again mentioned "the proper tune of the system", "a collaboration of all stakeholders", "high responsibility of all shareholder".

Equally, one participant stressed "the steady reforms", "professionalism", "autonomy of learners, academic staff and higher institutions". Alike, another contributor who argued that the Finnish system is advocating "practical teaching and learning skills", "critical thinking, research and problem learning", "formative assessments", "government financial support" and almost "the absence of gaps between educational levels" from the nursery level to the higher education. In the same way, the manager spoke about professionalism in preparing cadets for the professional life with less spending and in applying autonomy and freedom. The other candidates focused on critical thinking instead of memorising, the social contract where all are engaged in the process of learning and teaching.

To conclude participants have expressed a like for the Finnish higher education system because it has a strong foundation and it advocates critical thinking, autonomy, freedom.

\subsection{The Cultural, Social and Professional Challenges}

While studying the cultural, social and professional challenges that may face the application of the F.H.E.F in Oman, findings revealed the following. The Omani culture and society differ from the Finnish ones as Omani are more conservative despite being open to international expats. Unlike the Finnish society which is homogeneous but it is open to changes.

The same participant referred to the matter of parents and students' obsession with marks and not with the quality of education. In the same manner, the last speaker argued that the government should support to develop teachers on local and international levels. Likewise, this participant highlighted the need for professional and personal development, creating a culture of collaboration among academic staff as well as learners. Equally, the same contributor added that a professional society is a requirement in Oman to adopt the Finnish success factors (Chihiro, Kashif, \& Pekka, 2017). Not only this, but the speaker added a comment that Omani students are learning to get jobs for the sake of learning whereas learning is a life-long process to make positive change worldwide. On the other edge, lecture $\mathrm{M}$ questioned the method of applying the F.H.E.F and argued that "wise selection", "being open to change", and "Proper planning and strategies" are a requirement for this process.

In short, there are lots of socio-cultural and professional issues that may hinder the appliance of the Finnish higher education framework such as gender issues, planning, time management, collaboration, mindset. Not only this but also professionalism, job-oriented thinking and lack of personal development.

\subsection{The Perspectives of Adopting the Finnish Higher Education in Oman}

While investigating the views of using the F.H.E.F in Oman, outcomes resulted in the below. The Finnish system is inspiring and efficient to develop both learners and the academic staff on the one hand. On the contrary, it is a challenging task as culture and society are conservative in Oman. Which requires slow, steady adaptation, and efficient teaching methods, learning and assessment "formative assessment" and philosophy of "fun to learn" as one of the speakers argued. Respectively, another speaker reinforced the importance of providing a better teaching and learning environment, aligning learning process with industry, having professional staff and having an engaged professional society in education which aligns with what the Omani Ministry of Higher Education needs (Sultanate of Oman Ministry of Higher Education, 2017).

To sum up, question four findings show that the Finnish experience is inspiring as it uses critical thinking and is stirring the personal and professional development which would offer better teaching and learning environment in Oman for a better professional society as contributors argued: "create a better environment for learning and teaching". Moreover, it would require, "more skilled academic staff", "a professional society", "a culture of learning based on thinking, research and problem solving", "meet the expectations of society, industry and higher education quality assurance demands" according to the speakers.

\section{Discussions}

The report structure is as follow appliance of the Finnish Higher Education Framework in Oman, the Finnish Practical Teaching, Learning and Assessments Methods we can apply in Oman, the Cultural, Social and Professional Challenges and finally the perspectives of adopting the Finnish Higher Education in Oman. 


\subsection{The Adoption of the Finnish Higher Education Framework in Oman}

The idea of adopting the Finnish higher education framework in Oman as a focal research question sounds great and accepted by participants in both focus group sessions.

Responses reveal a high awareness from all participants that adopting the Finnish higher education framework in Oman it is not an easy task. "It is a challenge to apply the F.H.E.F in Oman, but it is an excellent framework," "I guess it is not a matter of applying the Finnish system but rather about adopting the ethos."

It is evident as cited above that participant expressed like to the concept of using the Finnish higher education framework in Oman. The Likert has various degrees as translated in the below phrases "an excellent framework", "good for sure", "good idea", "I do agree" and "I would agree". On the other hand, it is clear that there is a real challenge to apply the F.H.E.F in Oman according to participants as lecturer A reasons for example "I think it is a good start for the Omani system, but it is challenging."

The clarity of defiance for them is due to the nature of the Omani society which is very conservative when it comes to changes. Equally, challenges are due to the attitudes towards learning and teaching, lack of academic integrity, autonomy and personal development deficiency from the side of both learners and lecturers as the academician depicted it as "the lack of professionalism", while another participant named it "the absence of professional society".

It is evident that the challenge is also caused by the Know-how, and what to take from the Finnish experience "I guess it is not a matter of using the Finnish system but rather about adopting the ethos." Ethos refers to the whole philosophy behind the Finnish system including plans, strategies, means and goals.

In short, the idea of adopting the Finnish experience sounds tremendous and challenging while at the same time it requires from the Omani side clear planning, long-term strategies, know-how, and professionalism to ease the process of change.

\subsection{The Finnish Practical Teaching, Learning and Assessments Methods We Can Apply in Oman}

Participants support the idea to adopt the F.H.E.F in Oman arises from their like of the actual Finnish teaching, learning methods. Indeed, they see that the Finnish system uses effective teaching, learning and assessment methods that are beyond its success story.

For instance, participants argued that the Finns use "academic freedom", "giving time framework for learners", as well as "research and problem-based learning." While one speaker was very inquisitive on the one hand "Why would we adopt the Finnish Higher Education system in Oman?" and he carried on explaining that it is not a matter of a system but rather a question of using ethos: "It is a matter of adopting the ethos, not the system."

In here, it is evident that the philosophy behind the Finnish system that was named by "ethos" is what counts and not the whole system. In other words, it is the way Omani would look to change and from which angle the adaptation would fit the Omani context and make it effective as questioned by the same contributor "why would we put in the Finnish system?" Equally, the same participant thinks that F.H.E uses "Clear strategy regarding education that fits in the economy" and it advocates "Long-term plan and roles", which denotes that any change in the Omani system has to use long-term vision, fit in the economy and the social and cultural context.

Thus, the researcher infers that the Finnish higher education system is an inspiration from certain points, but it is also critical from the other end which implies a broader awareness in applying it within the Omani context. Having said that entails that the Omani system requires clear focused, long-term strategies and wise selection to apply the Finnish framework. In other words, Omanis have to ask what, how, who and when before adopting any success key factor in their system to ensure first whether it fits their context efficiently or not.

Concerning the focus group session, participants differently expressed their like for the Finnish practical teaching, learning and assessments methods as stated below:

Participants added that the Finnish system's success is due to the use of "practical skills", "bridging the gap between the educational stages" and relies on "the freedom of teaching and learning according to needs." In the same manner spoke one of them "proper tune of the system", "the great collaboration of stakeholders" and the focus on education. Likewise, he stressed "the high level of trust", and "parents' involvement in the teaching process".

Correspondingly, the academician valued "the slow, steady reforms of the F.H.E.S that date back to the 17th century" and "the influence of the neighbouring countries", "the focus on innovation", "competencies", "targeting international market" and "the well-being of individuals". 
Likewise, the Manager considers the Finnish system good at preparing candidates for the social and professional life, and valued "autonomy of both teacher and learner," "bridging the gaps between education stages."

In the same context, the decision maker cherished the Finnish higher practical teaching, learning and assessments methods in "focusing on knowledge, not memorisation" on "not giving the ready-made process of thinking" and he also stressed "the autonomy of the teacher and learner." The latter ended up that "the social contract guarantees independence, freedom, and well-being."

An analysis of the above-discussed outcomes implies that the Omani system has to tune the scheme by focusing on practical teaching methods, apply strict measures to recruit professional academic staff, give autonomy to teachers, learners and institutions. Likewise, create an environment of academic freedom, trust and collaboration between all stakeholder. Equally, it is a necessity to bridge the gaps between education levels and adopt a steady reform on all levels based on a culture of critical thinking and not memorisation. Similarly, government financial support to execute reforms is a requirement mainly when it comes to professional development and research centres around higher institutions for better learning.

In the same manner, education in Oman should create a balance between academia and society and sensitise people that learning is a life-long process for the well-being of all humans. In other words, students in Oman have to be aware that they are professional practitioners and are good citizens of this universe. Not only this but they have to be capable of making positive changes in the world.

To conclude, it is evident that all participants value the Finnish higher education for advocating freedom, autonomy, practical skills, critical thinking, research-based and problem-based learning and teaching. Meanwhile, the system applies trust as a social contract, responsibilities, competencies.

\subsection{The Cultural, Social and Professional Challenges}

According to all participants, the appliance of the F.H.E.F in Oman is not an easy task when it comes to the cultural, social and professional grounds.

For instance, concerning the socio-cultural challenges, the sampling session implies that the four participants agreed that there are lots of challenges in this area as quoted below: for example, one of them argued that "the gender issue is a hinder." Equally, another one said that "balancing academia with society is an area of improvement." While a third one added that "teamwork issues," "the Omani culture is entirely different from the Finnish one, we cannot change brains," "gender issues." Similarly, other points in the same context were raised by the focus group. To illustrate Speaker one argued that "the Omani culture is collectivist, with high power and weak leadership where students and parents are concerned with grades not the quality of learning." The last participant argued that "professionalism is also cultural" what one can infer from his speech is that being focused on grades impacts the learning and teaching process and makes professionalism questionable.

As referred above, it is evident that more cooperation between both males and males at higher institutions is a requirement to enable all learners to share ideas, collaborated, lead and solve problems and be ready for their professional career. Likewise, the equilibrium between the social and the academic is a necessity to reduce tension, stress and create a better environment for learning.

Concerning professionalism, findings revealed that there are lots of professional challenges. Indeed, participants stressed, "lecturers' development", "lack of academic integrity", "the gap between educational levels", and a policy of "Organisation". To explain, Omanisation is a policy issued by the Ministry of Manpower in Oman to prioritise work for Omanis in all domains, which makes a challenge for Omani management to recruit professional people as argued by the manager "Omanisation is a challenge for me as a manager."

Correspondingly, the academician expressed a louder opinion that supports what is said above such as "attitudes towards education", "not following the rules", "absence of collaboration", "lack of professional and personal development", "the inadequate academic integrity", and "mindset".

Results summary mentioned above denotes that applying the Finnish Higher education framework requires lots of changes in the mindset of both learners and educators to guarantee that learning process is up to date, stress-free, problem and research-based, critical, reflective and aligned with the social and vocational life. Equally, the personal and professional development of all stakeholders is a necessity and a life-long dictation. Correspondingly, recruitment policies should be strict and cater to professionalism and expertise and not to nationalities. Moreover, a culture of academic integrity, research-based learning should take place in all Omani institutions from primary to higher education and be reinforced by all stakeholders. 


\subsection{The Perspectives of Adopting the Finnish Higher Education in Oman}

Dealing with aspects of choosing Finnish Higher education in Oman, findings revealed that the idea sounds inspiring and functional. For instance, participants argued that it would help develop learners and educators, ensure good quality of education, Orient learning and teaching towards higher thinking skills and research. In the same manner, one speaker expressed a like for having a system based on the fun to learn where summative and formative assessment as practical tools help learners be on track. In the meantime, another speaker argued that applying the Finnish higher education system in Oman will be suitable for the development of all stakeholders, and the teaching environment. Correspondingly, a third one thinks that there are social challenges and government support is a must. On the other hand, according to a fourth speaker, it is not a matter of plug and play.

These outcomes entail that a wise adaptation and logical process that fit the context are the best ways to make any change. Similarly, the Finnish miracle sounds efficient for both learner and teacher but having professional lecturers and supporting society is a requirement to change brains.

The results of sampling group go hand in hand with the outcomes of the focus group in emphasising that applying the Finnish higher education framework in Oman would create a better qualified academic staff and a professional learning and teaching environment. Correspondingly, the other participants; the academician, the manager and the decision maker see that applying the Finnish system now sounds idealistic. They believe that adaptation requires planning, practice and slow, steady changes.

\section{Evaluation}

The results of this research are quite useful as they are realistic, valid and objective. Undeniably, all participants expressed their thoughts openly, positively and freely. Moreover, having two focus groups of 10 members from different nationalities, both males and females with various experience in education and industry worldwide and with different degree levels have strengthened the outcomes of the research. For instance, contributors discussed the research questions from broad perspectives not only from a Middle Eastern perspective which makes the study unbiased.

Likewise, applying the qualitative focus group method gave immediate ideas of improvement for the Omani Higher education system and clarified the requirements for using the Finnish higher education framework. Moreover, the research method used provided insights on the pros and cons of both systems (Finnish \& Omani) and how to go for constant, useful change without harming the specifics of Omani culture and society.

The limitations of the research paper are that it has used only two focus group session and in one Omani higher institution which is the International Maritime College Oman which may be beyond the limitations of the findings.

Based on the research goals and findings, the recommendations focus on two perspectives:

\section{Recommendations}

It is highly recommended to bridge the gap between the educational stages to ensure that students are to the level.

A step by step reform should take place in all educational organisations to advocate problem-based learning and research-oriented teaching within a precise alignment between learning mechanism and assessment processes. More specifically, course and assessments materials should include activities that boost thinking and problem-solving such as case studies, integrated research, practical learning following Bloom's taxonomy cognitive levels from remembering to creating to heighten higher thinking order skills.

Strict recruitment measures should be the passport to ensure professionalism among academic staff.

To be more specific, institutions in Oman have to focus on activities that encourage group work, leadership skills, and positive change. For instance, creating teams, inaugurating leaders, heartening societal work and adopting life-long learning philosophy and universal citizenship values are fundamental factors for success.

Further investigation into the learning styles of Omanis' students can help enhance learning and teaching in Oman and the Middle East.

Likewise, research on autonomy as a concept in the Omani institutional culture can add value to this investigation and improve higher education in Oman.

Finally, investigating the alignment of learning and teaching tools with assessment procedures would accomplish this study and strengthen education in Oman. 


\section{Conclusion}

Findings revealed that it is a good idea to use the Finnish Higher Education framework in Oman, but it is a challenging task according to almost all the participants. Similarly, results demonstrate that the Finnish higher educational system uses good practical teaching and learning methods that should take place in Oman such as critical thinking, problem-based and research-based learning, trust, autonomy, collaboration, and fair competition on the local and international basis. The latter finding meets with the literature provided that stressed the above concepts in learning (Suoranta \& Moisio, 2006). Additionally, the Omani system has to reinforce the use of formative assessment, the balance between the social and academic, provide a stress-free environment for better learning and involve society, industry and parents to maintain continuity and steadiness of development (Töytäri et al., 2017).

Likewise, the appliance of the Finnish experience requires patience, long-term strategies and government support because of culture, society and professionalism are areas of challenge that needs careful application. Alike, establishing a culture of reading, academic integrity and autonomy are key factors to enhance the learning process.

\section{References}

Alami, M. (2016). Causes of Poor Academic Performance among Omani Students. International Journal of Social Science Research, 4(1), 126. https://doi.org/10.5296/ijssr.v4i1.8948

BBC. (2016). Finnish higher education standard among world's best. Retrieved February 5, 2017, from http://www.goodnewsfinland.com/bbc-finnish-tertiary-education-among-world-s-best/

Black, P., \& Wiliam, D. (2008). Assessment and Classroom Learning. Assessment in Education: Principles, Policy \& Practice, 5(1), 7-74. https://doi.org/10.1080/0969595980050102

British Educational Research Association. (2011). Ethical Guidelines for Educational Research. Retrieved January 7, 2017, from http://content.yudu.com/Library/A1t9gr/BERAEthicalGuideline/resources/index.htm?referrerUrl=http\%252 53A\%25252F\%25252Fwww.yudu.com\%25252Fitem\%25252Fdetails\%25252F375952\%25252FBERA-Eth ical-Guidelines-2011

Business Insider. (2017). How Finland beats America on education. Retrieved May 26, 2017, from http://www.businessinsider.com/how-finland-beats-america-on-education-2016-11

Chihiro, W., Kashif, N., \& Pekka, N. (2017). Co-evolution between trust in teachers and higher education toward digitally-rich learning environments. Retrieved from http://www.elmenymuhely.hu/wp-content/uploads/JyväskyläCambridgeMathematicsKaleidoscope2704201 7.pdf

CNN. (2013). What Finland can teach America about education-Global Public Square. Retrieved May 26, 2017 ,

from http://globalpublicsquare.blogs.cnn.com/2013/12/03/what-finland-can-teach-america-about-education/

Diwan of Royal Court, \& D.G of telecommunication and Information System. (2016). Higher Education in the Sultanate of Oman. Retrieved April 24, 2017, from http://www.educouncil.gov.om/en/page.php?scrollto=start\&id=17

Ellen, H. (2017). Why Internationalisation Matters. Retrieved May 22, 2017, from https://blogi.karvi.fi/2017/03/30/why-internationalisation-matters/

Finland University. (2017). TEACHING AND LEARNING IN HIGHER EDUCATION-INTRODUCTION TO UNIVERSITY PEDAGOGY. Retrieved June 9, 2017, from http://www.finlanduniversity.com/service/teaching-learning-higher-education-introduction-university-peda gogy/

Gill, P., Stewart, K., Treasure, E., \& Chadwick, B. (2008). Methods of data collection in qualitative research: interviews and focus groups. British Dental Journal, 204, 291-295. https://doi.org/10.1038/bdj.2008.192

Halah, A. A., \& McGuire, P. (2015). 21st Century Standards and Curriculum: Current Research and Practice. Journal of Education \& Practice, 6(6), 150-155.

Melin, G., Zuijdam, F., Good, B., Angelis, J., Enberg, J., Fikkers, D. J., ... \& Zegel, S. (2015). Towards a future-proof system for higher education and research in Finland. Retrieved from http://www.minedu.fi/export/sites/default/OPM/Julkaisut/2015/liitteet/okm11.pdf 
Ministry of Education and Culture. (2017a). Evaluation of the Academy of Finland - OKM - Ministry of Education and Culture, Finland. Retrieved May 28, 2017, from http://minedu.fi/en/publication?pubid=URN:ISBN:978-952-263-225-8

Ministry of Education and Culture. (2017b). Quality of employment to be introduced as one of the funding criteria for higher education institutions - Article - OKM - Ministry of Education and Culture, Finland. Retrieved May 28, 2017, from http://minedu.fi/en/article/-/asset_publisher/tyoryhma-laadullinen-tyollistyminen-yhdeksi-korkeakoulujen-r ahoituskriteeriksi

Ministry of Education and Culture. (2017c). Vision for higher education and research in Finland 2030 - Article OKM - Ministry of Education and Culture, Finland. Retrieved May 28, 2017, from http://minedu.fi/en/article/-/asset_publisher/suomen-korkeakoulutukselle-ja-tutkimukselle-visio-2030

National Center on Education and the Economy. (2017). NCEE | Statistic of the Month: High Performance, Equity and Efficiency in Education. Retrieved June 19, 2017, from http://ncee.org/2017/03/statistic-of-the-month-high-performance-equity-and-efficiency-in-education/

Noella, M., \& Sally, K. (2006). IIER 16: Mackenzie and Knipe-research dilemmas: Paradigms, methods and methodology. Retrieved June 18, 2017, from http://www.iier.org.au/iier16/mackenzie.html

Onwuegbuzie, A. J. (2009). A Qualitative Framework for Collecting and Analyzing Data in Focus Group Research. International Journal of Qualitative Methods, 1-21.

Onwuegbuzie, A. J., \& Denham, M. (2011). Qualitative Data Analysis Techniques. Oxford Bibliographies. https://doi.org/10.1093/obo/9780199756810-0078

Pasi, S. (2015). Pasi Sahlberg-The Myth of Finnish Education. Retrieved from https://www.youtube.com/watch?v=RQzpiQCr2zA

Punch, K. F. (2009). Introduction to Research Methods in Education. London: Sage.

Sahlberg, P. (2011). Paradoxes of Educational Improvement: The Finnish Experience. Scottish Educational Review, 43(1), 3-23.

Sara, J. (2017). University of Eastern Finland awarded quality label-developing an open quality culture through long-term quality work-Karvi.fi. Retrieved May 22, 2017, from https://karvi.fi/en/2017/04/21/university-eastern-finland-awarded-quality-label-developing-open-quality-cul ture-long-term-quality-work/

Sean, C. (2016). Which country really has the cleverest students? Retrieved June 9, 2017, from http://www.bbc.com/news/business-37649892

Sultanate of Oman Ministry of Higher Education. (2017). Ministry of Higher Education-Oman. Retrieved May 28, 2017, from https://mohe.gov.om/InnerPage.aspx?id=3768F578-5F48-444C-9D24-E48671F378D9

Suoranta, J., \& Moisio, O.-P. (2006). Critical Pedagogy as Collective Social Expertise in Higher Education. International Journal of Progressive Education, 2(3). Retrieved from http://dergipark.gov.tr/download/article-file/237115

The Fulbright Center. (2017). Higher Education in Finland (The Fulbright Center). Retrieved May 27, 2017, from http://www.fulbright.fi/en/guide/higher-education

The World FactBook. (2017). The World Factbook—Central Intelligence Agency. Retrieved May 27, 2017, from https://www.cia.gov/library/publications/the-world-factbook/geos/fi.html

Töytäri, A., Tynjälä, P., Piirainen, A., \& Ilves, V. (2017). Higher education teachers' descriptions of their own learning: a quantitative perspective. Higher Education Research \& Development, 36(6), 1295-1304. https://doi.org/10.1080/07294360.2017.1303455

Turku, A. M. K. (2014). Closer Cooperation with Oman-Turku University of Applied Sciences. Retrieved June 9, 2017, from https://www.tuas.fi/en/news/48/closer-cooperation-oman/

UNESCO. (2015). Education for all 2015 National Review: Viet Nam. 1-67. Retrieved from http://unesdoc.unesco.org/images/0023/002327/232770e.pdf

William, D. (2014). OPINION: How Finland broke every rule-and created a top school system-The Hechinger Report. Retrieved May 22, 2017, from http://hechingerreport.org/how-finland-broke-every-rule-and-created-a-top-school-system/ 
World Economic Forum. (2017). Which countries have the best higher education and training for business? Retrieved June

19 ,

2017 ,

from

https://www.weforum.org/agenda/2015/07/which-countries-have-the-best-higher-education-and-training-for -business/

Yarahmadi, F., \& Magd, H. A. E. (2016). Entrepreneurship Infrastructure and Education in Oman. Procedia-Social and Behavioral Sciences, 219, 792-797. https://doi.org/10.1016/j.sbspro.2016.05.079

Zouhaier. S. (2017). How to apply the Finnish higher educational framework in the middle east? Requirements, challenges, and perspectives; the case of Oman. A research Project submitted for the programme: Masters in the Art of Learning and Teaching at Roehampton University. Department of the Education University of Roehampton London.

\section{Notes}

Note 1. The Programme for International Student Assessment

Note 2. The Organisation for Economic Co-Operation and Development

Note 3. Gross Domestic Product

Note 4. Gulf Cooperation Council

Note 5. Higher Education Institutions

Note 6. Finnish Higher Education Framework

\section{Copyrights}

Copyright for this article is retained by the author, with first publication rights granted to the journal.

This is an open-access article distributed under the terms and conditions of the Creative Commons Attribution license (http://creativecommons.org/licenses/by/4.0/). 